\title{
EFFECTS OF SOURCE DOPING PROFILE ON DEVICE CHARACTERISTICS OF LATERAL AND VERTICAL TUNNEL FIELD-EFFECT TRANSISTORS
}

\author{
Luu The Vinh ${ }^{1}$, Nguyen Dang Chien ${ }^{2,3}$, * \\ ${ }^{1}$ Faculty of Electronic Technology, Industrial University of Ho Chi Minh City, \\ Ho Chi Minh City 727905, Vietnam \\ ${ }^{2}$ Faculty of Physics, University of Da Lat, Lam Dong 671463, Vietnam \\ ${ }^{3}$ Department of Electrical Engineering, National Chi Nan University, Nantou 54561, Taiwan \\ *Email:ndchien@ymail.com
}

Received: 26 March 2014; Accepted for publication: 20 September 2014

\begin{abstract}
The source doping engineering, the low bandgap material and the vertical tunneling structure have recently been considered as most effective techniques to resolve the on-current issue in tunnel field-effect transistors (TFETs). In this paper, the effects of source doping profile, including the concentration and gradient, on the device characteristics are adequately elucidated in lateral and vertical TFETs using low bandgap germanium to allow a comprehensive comparison between the two major TFET architectures for the first time. Similar dependences of the on-current on the source concentration are observed in lateral and vertical TFETs, except that the on-current of vertical TFETs is always greater than that of lateral TFETs approximately one order of magnitude. With different contributions of the lateral and vertical tunneling components in the subthreshold region, the subthreshold swing of vertical TFETs first decreases at small concentrations, then increases at medium values, and finally decreases again at high concentrations, whereas that of lateral counterparts always decreases exponentially with increase in the source concentration. The on-current of lateral TFETs is significantly decreased, while that of vertical TFETs is almost invariable with increasing the source doping gradient. With competitive advantages of the vertical TFET architecture in on-current, subthreshold swing and device fabrication, vertical TFETs using low bandgap semiconductors are promising for use in low power applications.
\end{abstract}

Keywords: source engineering, source doping effect, lateral tunneling, vertical tunneling, tunnel field-effect transistor.

\section{INTRODUCTION}

Owing to the breakthrough of $60 \mathrm{mV} /$ decade subthreshold swing at room temperature, tunnel field-effect transistors (TFETs) have been considered as an attractive candidate for low power and high performance applications compared to conventional metal-oxide-semiconductor 
field-effect transistors (MOSFETs) which are subjected to the Boltzmann limit of $60 \mathrm{mV} / \mathrm{decade}$ $[1,2]$. Differently from standard MOSFETs, typical TFETs are always operated in highly reverse-biased conditions to result in significantly low static power dissipations [3, 4]. Based on the band-to-band tunneling (BTBT) of carriers through the forbidden-band gap, in the other hand, the tunnel probability in TFETs is highly controlled by the applied voltages to produce a steep subthreshold swing [4, 5]. A subthreshold swing of less than $60 \mathrm{mV} /$ decade is the key requirement to scale the power supply voltage for low dynamic power consumptions since a transistor with a steep subthreshold swing only requires a less gate voltage for a given on-off current ratio.

Since the tunnel probability depends strongly on the tunnel barrier width and height, the oncurrent of TFETs is highly relied on the energy bandgap of semiconductors. Numerous researches have been performed to properly control the tunnel barrier for improving the oncurrent and subthreshold swing [5 - 7]. Unfortunately, the on-current of silicon-based TFETs is still relatively low because of the high bandgap of silicon [8]. Enhancing the on-current becomes the most imperative challenge in TFET devices. Advanced techniques proposed to enhance the on-current of TFETs usually involve in the engineering of the tunnel barrier width and/or the tunnel barrier height [9-11]. One of the most effective techniques is the use of low-bandgap materials in TFETs. With using low-bandgap materials, the tunnel barrier is not only lowered but also narrowed to extremely boost the on-state tunneling current $[6,11,12]$. To further ameliorate the on-current and the subthreshold swing, a new TFET architecture has been proposed to produce the vertical tunneling in the direction perpendicular to the gate oxide layer $[13,14]$. Because the vertical tunneling occurs within the heavily-doped source, the subthreshold swing is significantly decreased. It is noted that the tunneling area, which is located at the source-channel junction, is uncontrollable in the traditional p-i-n TFET structure. Differently, the tunneling region in vertical TFETs can flexibly be extended by adjusting the gate-source overlap length to enhance the on-current. Using low-bandgap semiconductors in vertical tunnel green transistors has obviously demonstrated an excellent combination to simultaneously maximize the on-current and minimize the subthreshold swing [15].

Because the source doping determines the potential profile and hence the tunnel width of tunnel junctions, the device characteristics depend strongly on the source doping profile in lateral and vertical TFET devices. It is shown that, in general, the on-current and the subthreshold swing are improved with increasing the source concentration. In lateral TFETs, the source doping gradient is also the key element to control the device characteristics [16], whereas its role in vertical TFETs still remains uncertainty. Furthermore, a comprehensive investigation for effects of source doping profile on the lateral and vertical TFET characteristics has not been presented in parallel for adequate comparisons. Therefore, the roles of source doping profile in lateral and vertical TFETs has not been properly elucidated and compared to provide useful information for designing these potential semiconductor transistors.

In this paper, the effects of source doping profile on the characteristics of lateral and vertical TFETs are explored in detail by two-dimensional simulations [17] to provide the overall understanding on the roles of source doping profile in designing lateral and vertical TFETs. Associated physical explanations are accordingly given in term of the energy-band diagram to explicitly clarify the physics of devices. The paper is divided into five sections, including the Introduction (Section 1) and the Conclusions (Section 5). Section 2 describes the device structures and physical models used in the investigations. The effects of source concentration are detailed in Section 3, whereas the effects of source doping gradient are presented in Section 4. 


\section{DEVICE ARCHITECHTURES AND PHYSICAL MODELS}

Figure 1 shows typical lateral and vertical homojunction TFET structures with using lowbandgap germanium for boosting the on-current $[6,9,12]$. Lateral and vertical TFETs are also widely known as point and line TFETs, respectively, because the tunneling occurs at a narrow source corner in lateral TFETs while it appears along the source surface beneath the gate oxide as shown in the figure. Although germanium $(\mathrm{Ge})$ is an indirect bandgap semiconductor, the direct tunneling component is still a decisive contribution in Ge TFETs because its direct bandgap $(0.8 \mathrm{eV})$ is only slightly higher than the indirect bandgap $(0.66 \mathrm{eV})$ [18]. For all TFET devices, a single-gate structure with $3 \mathrm{~nm}$ physical oxide thickness of $\mathrm{HfO}_{2}$ and a metal gate work function of $4.2 \mathrm{eV}$ were used. A doped $\mathrm{n}^{+}$drain of $5 \times 10^{18} \mathrm{~cm}^{-3}$ and a $100 \mathrm{~nm} \mathrm{n}$-channel of $10^{17} \mathrm{~cm}^{-3}$ were fixed to minimize the ambipolar current [8], whereas the source doping concentration and gradient are appropriately varied for study purposes. In the vertical TFETs, the gate fully overlaps the channel with a gate-source overlap length of $50 \mathrm{~nm}$ to maximize the on-current [19].

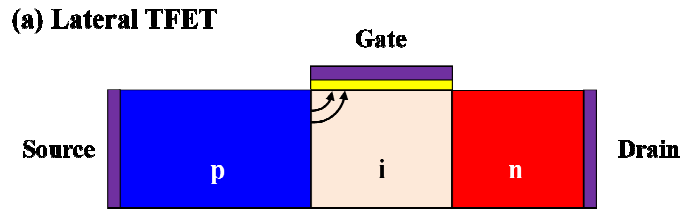

(b) Vertical TFET

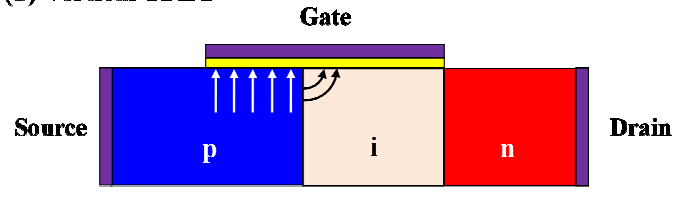

Figure 1. Schematic structures of (a) lateral and (b) vertical Ge tunnel field-effect transistors. Arrows show the directions of possible tunneling processes.

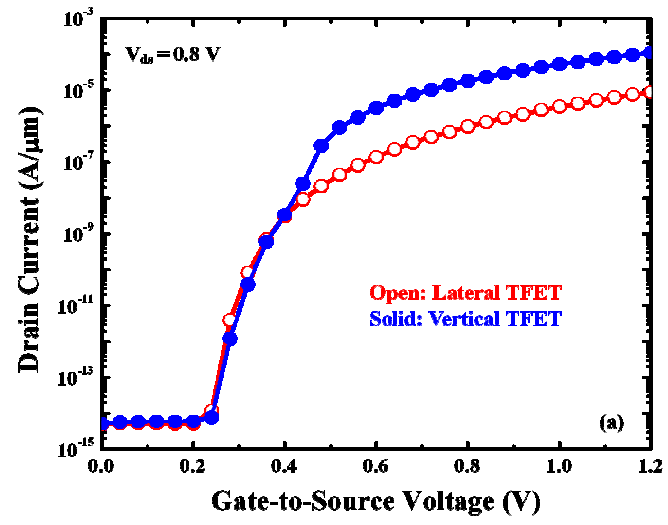

Figure 2. Current-voltage curves of lateral and vertical TFETs with a mild source doping and a reasonable gradient of $10^{19} \mathrm{~cm}^{-3}$ and $2 \mathrm{~nm} /$ decade, respectively.

The electrical characteristics of the TFETs are analyzed by using commercial twodimensional device simulator [17] in which the direct BTBT generation rate is calculated by the Kane's model [20]. The model integrated in the simulator has been experimentally validated in SiGe-based tunnel devices $[9,12,18,21]$ for a wide range of operating temperature [3]. In the Kane's model, the direct BTBT rate is expressed as: [20]

$$
G_{\text {ВТВТ }}=A \frac{\xi^{2}}{E_{g}^{1 / 2}} \exp \left(-B \frac{E_{g}^{3 / 2}}{\xi}\right),
$$

where $\mathrm{E}_{\mathrm{g}}$ and $\xi$ are the semiconductor bandgap and tunnel junction electric field, respectively. In a non-uniform electric field, the electric field term in eq. (1) is determined non-locally along the tunnel path to properly estimate the tunneling rate [22]. Material parameters A and B depending on the carrier effective masses have been properly calculated for germanium [18, 23]. Eq. (1) shows that the BTBT generation depends explicitly on the energy bandgap and the electric field which is determined by the tunnel width. In all simulations, the bandgap narrowing, the FermiDirac distribution and the Shockley-Read-Hall generation-recombination are considered. 
Additionally, to focus on the physical considerations of the source doping profile effects in the TFETs, the trap-assisted tunneling is not taken into account because the trap-assisted tunneling
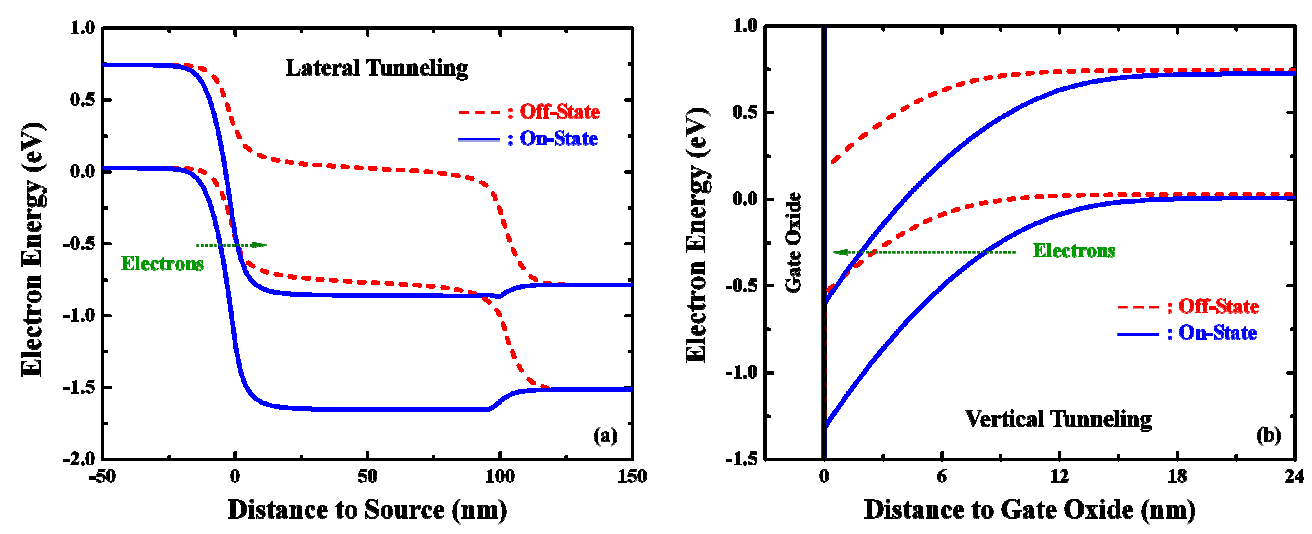

Figure 3. Energy-band diagrams of (a) lateral and (b) verticalTFETs at on- and off-states.

is process sensitive and it is less important in low bandgap Ge TFETs [12, 24].

To examine the operations and provide a preliminary comparison, Fig. 2 shows the simulated current-voltage characteristics of the lateral and vertical TFETs. A mild source concentration of $10^{19} \mathrm{~cm}^{-3}$ and a reasonable doping gradient of $2 \mathrm{~nm} /$ decade are defined in the simulations. Generally, both kinds of TFETs achieve a very low off-current and subthreshold swing, which is basically attributed to the BTBT mechanism in the reverse-biased p-i-n junctions. Notably, the on-current of the vertical TFET is significantly higher than that of the lateral counterpart. However, the current-voltage characteristics of the lateral and vertical TFETs are almost identical in the subthreshold regions. Because the onset of the lateral tunneling is more premature than that of the vertical tunneling [19], the lateral tunneling dominates the subthreshold region, whereas the vertical tunneling mainly contributes to the on-state current in the vertical TFET. Figure 3 plots the energy-band diagrams at off- and on-states to explain the working principles of the lateral and vertical TFETs. In the lateral TFET (Fig. 3(a)), a wide tunnel barrier is formed by the channel potential flat zone at off-state to prevent the tunneling leakage current. At the on-state with high applied gate voltages, the source-channel tunnel junction is narrowed to allow the lateral tunneling of electrons from the source valence band to the channel conduction band. In the vertical TFET (Fig. 3(b)), the vertical band bending at offstate is insufficient to enable the band-to-band tunneling. At high gate voltages, however, the significant vertical band bending opens up the tunneling band to turn the device on. Electrons tunnel vertically from the source center to the source surface before swept toward the drain. Because the tunneling in the vertical TFET occurs within the heavily-doped source, the tunnel width is smaller and the tunnel area is larger than those in the lateral TFET [13, 19]. Therefore, the on-current is significantly enhanced in the vertical TFET device. 

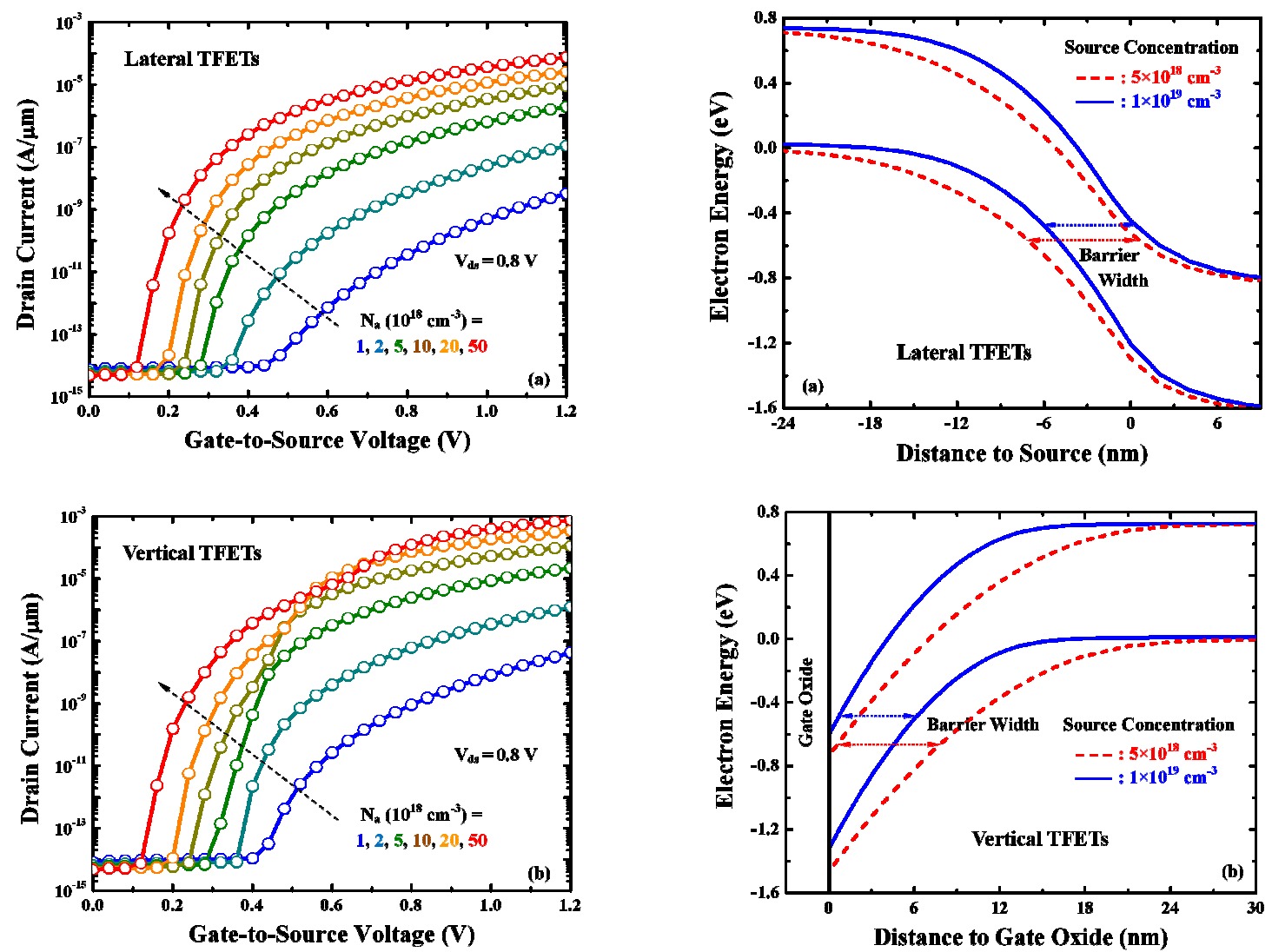

Figure 4. Current-voltage curves of (a) lateral and (b) vertical TFETs with various source doping concentrations.

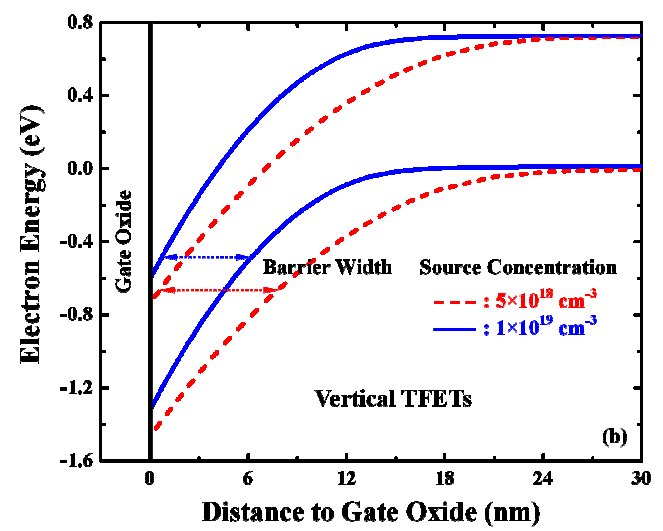

Figure 5. Energy-band diagrams of (a) lateral and (b) vertical TFETs with different source concentrations.

\section{EFFECTS OF SOURCE CONCENTRATION}

Because the on-off switching of either lateral or vertical TFETs is basically controlled by the band-to-band tunneling at source side, the source concentration plays a key factor in determining the device characteristics of TFETs. Generally, a higher source concentration results in a stronger band bending at the depletion region of tunnel junction. Therefore, the tunnel barrier width is narrower and the on-off transition of the tunnel barrier is more abrupt to produce the higher on-current and smaller subthreshold swing in heavier source TFETs regardless of their lateral or vertical structure $[6,16,19]$. However, a comprehensive comparison of source concentration effects on the device characteristics in lateral and vertical TFETs has not been reported adequately in the scientific literature. In this section, the effects of source concentration are investigated and compared properly in the lateral and vertical TFETs to provide meaningful guidelines for the design of TFET devices. For proper investigations of source concentration effects, the source doping gradient is still fixed at the reasonable value of $2 \mathrm{~nm} /$ decade to minimize effects of doping gradient.

Figure 4 shows the current-voltage characteristics of the lateral and vertical TFETs with various source concentrations. In both the lateral and vertical TFETs, the on-current and 
subthreshold swing are significantly improved by increasing the source concentration. For the same source concentration, the on-current of the vertical TFETs is always greater than that of the lateral counterparts. However, the subthreshold swing is almost similar because the lateral tunneling dominates the subthreshold regions in the lateral and vertical TFETs. To physically explain the increase of on-current and the decrease of subthreshold swing when increasing the source concentration, Fig. 5 plots the on-state energy-band diagrams in lateral and vertical directions of the lateral and vertical TFETs, respectively, with two different source concentrations. In both the lateral and vertical TFETs, the higher doping concentration applied at the source produces the narrower tunnel width. As a result, the on-state current is higher and the subthreshold swing is lower in the heavier source TFET. For better comparisons, Fig. 6 plots the on-current and minimum subthreshold swing against the source concentration in the lateral and vertical TFETs. As shown in Fig. 6(a), the dependence of the on-current on the source concentration in the vertical TFETs exhibits the same trend as that in the lateral TFETs. For any source concentration, the on-current of the vertical TFETs is greater than that of the lateral TFETs approximately one order of magnitude. When the source concentration is small, the oncurrent extremely depends on the source concentration. The on-current becomes saturated at high source concentrations, which is due to the saturation of the tunnel width [6]. In view point of the on-current boosting, one should consider other techniques rather than increasing the source concentration once it reaches to relatively high values. However, the dependences of subthreshold swing on the source concentration are quite different between the lateral and vertical TFETs as shown in Fig. 6(b).
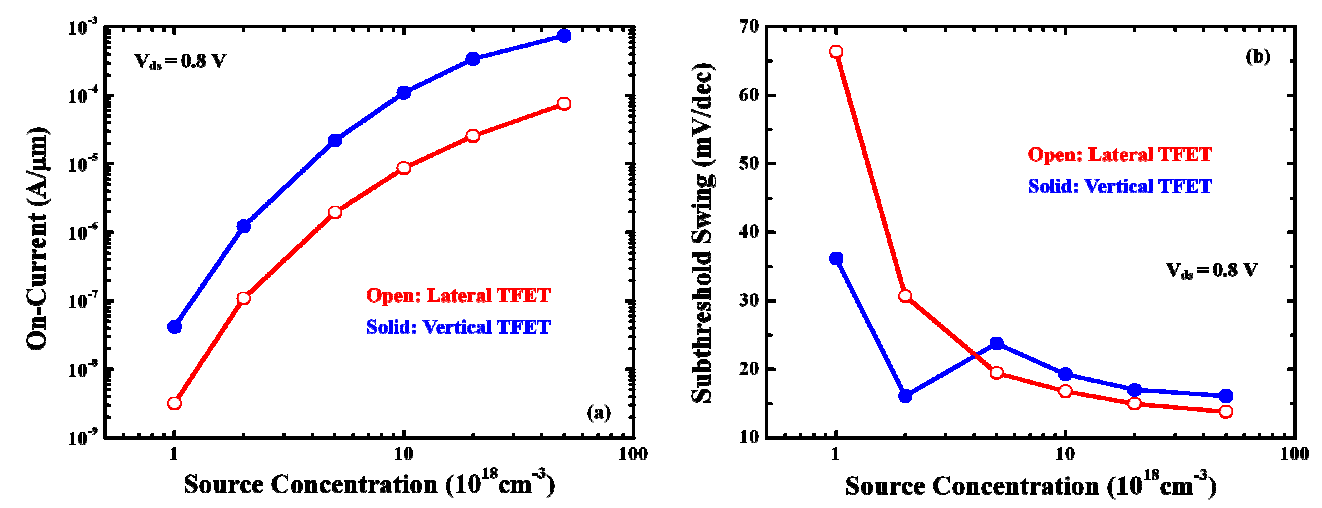

Figure 6. On-state energy-band diagrams of (a) lateral and (b) vertical TFETs with different source concentrations.

In the lateral TFETs, the subthreshold swing exponentially decreases as the source concentration increases. The decrease of subthreshold swing is much more pronounced at small source concentrations and it reaches to the saturation regime at high concentrations. Differently in the vertical TFETs, the subthreshold swing is first decreased, then increased and finally decreased again when increasing the source concentration from $10^{18}$ to $5 \times 10^{19} \mathrm{~cm}^{-3}$. In order to understand this extraordinary dependence of the subthreshold swing, it is noted that the contribution of the lateral tunneling to the drain current in the subthreshold region of the vertical TFETs increases with increase in the source concentration [19]. At extremely small source concentrations, the vertical tunneling dominates the drain current in both the subthreshold and on-state regions. Therefore, the subthreshold swing is rapidly decreased with increasing the source concentration up to $2 \times 10^{18} \mathrm{~cm}^{-3}$. For high source concentrations, the vertical tunneling only dominates at on-state, whereas the lateral tunneling mainly contributes to the drain current 
in the subthreshold region. For this reason, the values of subthreshold swing in the vertical and lateral TFETs are almost comparable at source concentrations higher than $5 \times 10^{18} \mathrm{~cm}^{-3}$. For lateral TFETs with source concentrations from $2 \times 10^{18}$ to $5 \times 10^{18} \mathrm{~cm}^{-3}$, both the lateral tunneling and the vertical tunneling govern the drain current in the subthreshold condition. However, while the role of the lateral tunneling increases, that of the vertical tunneling decreases as the source concentration increases. Because the saturation of subthreshold swing of the vertical tunneling component is more premature than that of the lateral tunneling component, the subthreshold swing increases as the source concentration increases from $2 \times 10^{18}$ to $5 \times 10^{18} \mathrm{~cm}^{-3}$.

\section{EFFECTS OF SOURCE DOPING GRADIENT}

Section 3 has presented the effects of source concentration on the device characteristics of the lateral and vertical TFETs with a fixed source doping gradient. Previous researches showed that the source doping gradient also exhibits strong effects on the device performance of conventional p-i-n TFETs $[16,25]$. This is because the tunneling, which helps in turning on TFETs, occurs at the source-channel junction. The higher abruptness of source-channel junction results in the stronger junction electric field to achieve the steeper on-off switching and the higher on-current. In the vertical TFETs, however, the lateral and vertical tunneling components all contribute to the drain current. Because the vertical tunneling does not occur at the sourcechannel junction, the roles of source-channel junction abruptness may be very different between the lateral and vertical TFETs. Unfortunately, the role of source doping gradient on the device characteristics of the vertical TFETs has not been reported so far. In this section, the effects of source doping gradient are adequately elucidated in the lateral and vertical TFETs. As shown in previous section, a high source doping concentration is required to maximize the on-current and minimize the subthreshold swing in the lateral and vertical TFETs. The simulations in this section thus employ a high source concentration of $5 \times 10^{19} \mathrm{~cm}^{-3}$ in these two TFET structures.
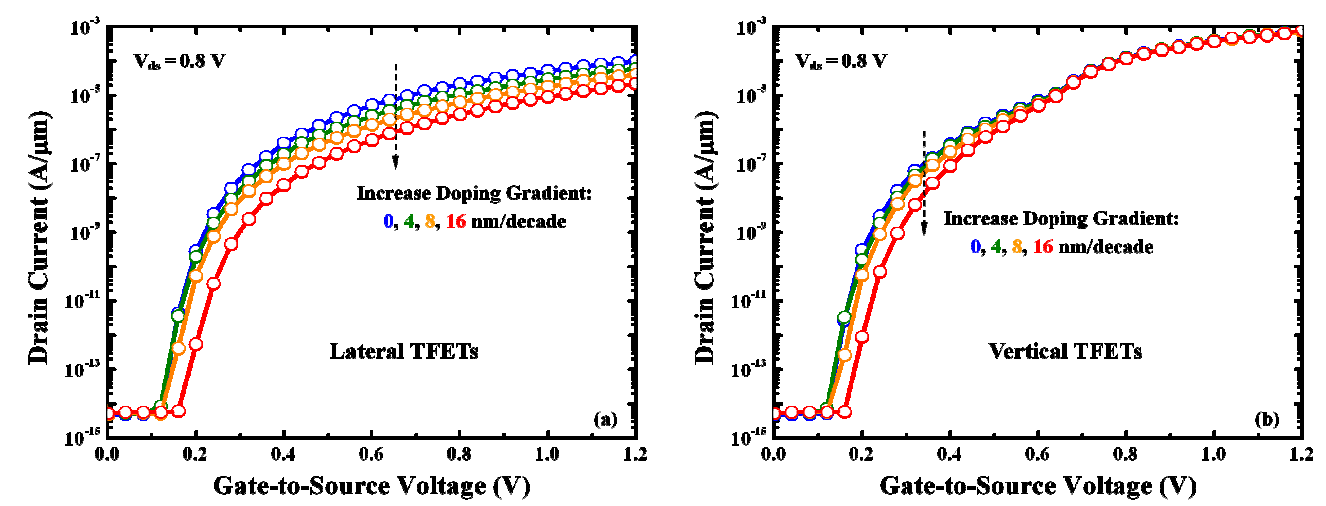

Figure 7. Current-voltage characteristics of (a) lateral and (b) vertical TFETs with various source doping gradients.

To investigate the effects of source doping gradient, Fig. 7 shows the current-voltage curves of the lateral and vertical TFETs with various source doping gradients. For the lateral TFETs shown in Fig. 7(a), the on-current is decreased with increasing the source doping gradient. In previous investigations on the source doping gradient effects in lateral TFETs using $20 \mathrm{~nm} \mathrm{SiO}{ }_{2}$ as the gate dielectric material [15], the on-current is decreased approximately three orders of magnitude when increasing the source doping gradient from 0 to $16 \mathrm{~nm} /$ decade. The 
degradation of on-current and subthreshold swing by the decrease of junction abruptness is considerably mitigated in this lateral TFET structure, which is mainly attributed to the stronger capacitive coupling of the gate and tunnel junction by using the high-k gate dielectric. As shown in Fig. 7(b), the role of source doping gradient in determining the current-voltage characteristics of the vertical TFETs is quite different from that of the lateral counterparts. The on-state regions, which are mainly contributed by the vertical tunneling, are almost identical for every source doping gradient. Similarly as observed in the lateral TFETs, however, the subthreshold region is altered under varying the source doping gradient because the lateral tunneling dominates in this region. The almost invariability of the on-current in the vertical TFETs irrespective of the source doping gradient is the direct result of the fact that the vertical tunneling of carriers does not occur laterally at the source-channel junction, but vertically from the center to the surface within the gate-overlapped source.
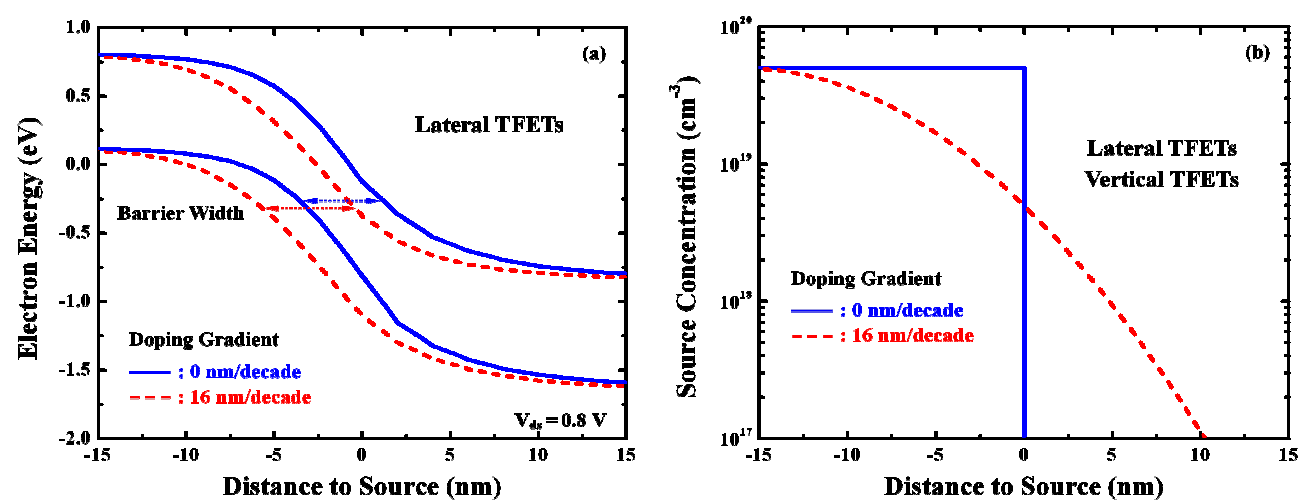

Figure 8. (a) On-state energy-band diagrams and (b) lateral source doping profiles of lateral TFETs with different source doping gradients.

The performance degradation in the lateral TFETs by the decrease of the source-channel junction abruptness can be properly explained by the on-state energy-band diagrams plotted in Fig. 8(a). For further illustrating the energy-band diagrams, Fig. 8(b) shows the corresponding source doping profiles extracted laterally around the source-channel junction. For the small junction abruptness with the doping gradient of $16 \mathrm{~nm} /$ decade, the energy bands at the tunnel junction are relatively smooth to form the wide tunnel width which results in the low on-state tunneling current. For the abrupt source-channel junction, the band bending is more abrupt to produce the narrow tunnel path for the high tunneling current. Although the on-current degradation by the decrease of the tunnel junction abruptness is highly diminished by the use of high-k gate dielectric, this on-current lowering is still significant to be carefully considered in the TFET design. In practical fabrications, it is costly and time-consuming to fabricate abrupt junctions with small doping gradients. Furthermore, the doping and associated gradient fluctuations can cause considerable degradations of device and circuit reliabilities, especially at high doping density and abruptness which are indispensably required in the lateral TFETs. For achieving high performance, avoiding degradations of device performance and reliability as well as reducing fabrication processes, the vertical TFET structure is the feasible choice in future low power and high performance applications. 


\section{CONCLUSIONS}

Two-dimensional simulations have been properly demonstrated to investigate the effects of source doping profile, including the source concentration and gradient, on the device characteristics of the lateral and vertical Ge TFETs. The roles of source concentration in the oncurrent and subthreshold swing have been comprehensively compared between the lateral and vertical TFET architectures for the first time. Different effects of source doping gradient associated with different device physics have been adequately elucidated in the lateral and vertical TFETs. With distinguished advantages in device performance and fabrication, the vertical TFET architecture with low bandgap semiconductors exhibits a potential technique for use in low power and high performance digital integrated circuits.

Acknowledgements. The authors would like to thank the Nano Devices and Integrated Circuits Laboratory at National Chi Nan University for computer time and facilities.

\section{REFERENCES}

1. Choi W. Y., Park B. G., Lee J. D., and Liu T. J. K. -Tunneling field-effect transistors (TFETs) with subthreshold swing (SS) less than $60 \mathrm{mV} / \mathrm{dec}$, IEEE Electron Device Lett. 28 (2007) 743-745.

2. Esseni D., Guglielmini M., Kapidani B., Rollo T., and Alioto M. - Tunnel FETs for ultralow voltage digital VLSI circuits: Part I -device-circuit interaction and evaluation at device level, IEEE Trans. Very Large Scale Integr. (VLSI) Syst., in press.

3. Reddick W. M. and Amaratunga G. A. J. - Silicon surface tunnel transistor, Appl. Phys. Lett. 67 (1995) 494-496.

4. Wang P. F., Hilsenbeck K., Nirschl Th., Oswald M., Stepper Ch., Weis M., SchmittLandsiedel D., and Hansch W. - Complementary tunneling transistor for low power application, Solid-State Electron.48 (2004) 2281-2286.

5. Chien N. D. and Vinh L. T. - Design optimization of extremely short channel graded $\mathrm{Si} / \mathrm{SiGe}$ heterojunction tunnel field-effect transistors for low power applications, Journal of Science and Technology 51 (6) (2013) 757-768.

6. Toh E.-H., G. H. Wang, G. , and Y.-C. Yeo - Device physics and design of germanium tunneling field-effect transistor with source and drain engineering for low power and high performance applications, J. Appl. Phys. 103 (2008) 104504-104504-5.

7. Chien N. D., C.-H. Shih and L. T. Vinh - Drive current enhancement in tunnel field-effect transistors by graded heterojunction approach, J. Appl. Phys. 114 (2013) 094507-0945076 [Erratum114 (2013) 189901-189901-1].

8. Manti S., Knoll L., Schmidt M., Richter S., Nichau A., Trellenkamp S., Schafer A., Wirths S., Blaeser S., Buca D., and Zhao Q.-T. - Si based tunnel field effect transistors Recent achievements, International Conference on Ultimate Integration on Silicon (2013) $15-20$.

9. Krishnamohan T., Donghyun K., Raghunathan S., and Saraswat K. - Double-gate strained-Ge heterostructure tunneling FET (TFET) with record high drive currents and 60mV/dec subthreshold slope, International Electron Devices Meeting (2008) 1-3.

10. Choi W. Y. and Lee W. - Hetero-gate-dielectric tunneling field-effect transistors, IEEE 
Trans. Electron Devices 57 (2010) 2317-2319.

11. Shih C.-H. and Chien N. D.- Sub-10-nm tunnel field-effect transistor with graded Si/Ge heterojunction, IEEE Electron Device Lett. 32 (2011) 1498-1500.

12. Nayfeh O. M., Hoyt J. L., Antoniadis D. A. - Strained-Si ${ }_{1-x} G_{x} / S i$ band-to-band tunneling transistors: impact of tunnel junction germanium composition and doping concentration on switching behavior, IEEE Trans. Electron Devices 56 (2009) 2264-2269.

13. Vandenberghe W. G., Verhulst A. S., Groeseneken G., Soree B., and Magnus W. Analytical model for a tunnel field-effect transistor, IEEE Mediterranean Electrotechnical Conference (2008) 923-928.

14. Wang W., Wang P.-F., Zhang C.-M., Lin X., Liu X.-Y., Sun Q.-Q., Zhou P., and Zhang D. W. - Design of U-shape channel tunnel FETs with SiGe source regions, IEEE Trans. Electron Devices 61 (2014) 193-197.

15. Hu C. - Green transistor as a solution to the IC power crisis, International Conference on Solid-State and Integrated Circuit Technology (2008) 16-20.

16. Wang P.-F., Nirschl T., Schmitt-Landsiedel D., and Hansch W. - Simulation of the Esakitunneling FET, Solid-State Electron. 47 (2003) 1187-1192.

17. Synopsys MEDICI User's Manual, Synopsys Inc., Mountain View, CA, 2010.

18. Kao K.-H., Verhulst A. S., Vandenberghe W. G., Sorée B., Groeseneken G., and Meyer K. D.- Direct and indirect band-to-band tunneling in germanium-based TFETs, IEEE Trans. Electron Devices 59 (2012) 292-301.

19. Shih C.-H. and Chien N. D. - Design and modeling of line-tunneling field-effect transistors using low-bandgap semiconductors, IEEE Trans. Electron Devices 61 (2014) 1907-1913.

20. Kane E. O. - Theory of tunneling, J. Appl. Phys. 32 (1961) 83-91.

21. Shih C.-H. and Chien N. D. - Physical operation and device design of short-channel tunnel field-effect transistors with graded silicon-germanium heterojunctions, J. Appl. Phys. 113 (2013) 134507-134507-7.

22. Peng J. Z., Haddad S., Hsu J., Chen J., Longcor S., and Chang C. - Accurate simulation on band-to-band tunneling induced leakage current using a global non-local model, International Conference on Solid-State and Integrated Circuit Technology (1995) 141143.

23. Chien N. D., Vinh L. T., Kien N. V., Hsia J.-K., Kang T.-S., and Shih C.-H. - Proper determination of tunnel model parameters for indirect band-to-band tunneling in compressively strained $\mathrm{Si}_{1-\mathrm{x}} \mathrm{Ge}_{\mathrm{x}}$ TFETs, IEEE International Symposium on NextGeneration Electronics (2013) 67-70.

24. Vandooren A., Leonelli D., Rooyackers R., Hikavyy A., Devriendt K., Demand M., Loo R., Groeseneken G., and Huyghebaert C. - Analysis of trap-assisted tunneling in vertical Si homo-junction and SiGe hetero-junction tunnel-FETs, Solid-State Electron. 83 (2013) $50-55$.

25. Jeon K. - Band-to-band tunnel transistor design and modeling for low power applications, Ph.D. Dissertation, University of California, Berkeley (2012) 16-17. 


\title{
TÓM TẮT \\ ẢNH HƯỞNG CỦA BIÊN DẠNG TẠP CHÂT CỰC NGUỒN TỚI ĐẠC TÍNH HOẠT ĐỘNG CỦA CÁC TRANZITO XUYÊN HẦM NGANG VÄ DỌC
}

\author{
Lưu Thế Vinh ${ }^{1}$, Nguyễn Đăng Chiến ${ }^{2,3, *}$ \\ ${ }^{1}$ Khoa Công nghệ Điện tử, Đại học Công nghiệp TP. Hồ Chí Minh, TP. Hồ Chí Minh 727905 \\ ${ }^{2}$ Khoa Vật lý, Đại học Đà Lạt, Lâm Đồng 671463 \\ ${ }^{3}$ Khoa Kỹ thuật điện, Đại học Quốc lập Ký Nam, Nam Đầu 54561, Đài Loan \\ *Email: ndchien@ymail.com
}

Kĩ thuật pha tạp cực nguồn, vật liệu vùng cấm nhỏ và cấu trúc xuyên hầm dọc đang được xem là những phương pháp hiệu quả nhất để khắc phục vấn đề dòng mở (on-current) thấp trong các tranzito trường xuyên hầm. Nghiên cứu này làm sáng tỏ những ảnh hưởng của nồng độ và độ biến thiên tạp chất cực nguồn tới đặc tính hoạt động của tranzito trường xuyên hầm ngang và dọc sử dụng gecmani có vùng cấm nhỏ, qua đó cho phép so sánh một cách toàn diện các khía cạnh vật lí và đặc tính của hai cấu trúc chính của tranzito trường xuyên hầm. Nghiên cứu chỉ ra rằng, sự phụ thuộc của dòng mở vào nồng độ tạp chất cực nguồn là như nhau trong cả hai loại tranzito trường xuyên hầm ngang và dọc, ngoại trừ dòng mở của tranzito trường xuyên hầm dọc luôn lớn hơn dòng mở của tranzito trường xuyên hầm ngang khoảng mười lần. Do mức độ đóng góp khác nhau của các thành phần xuyên hầm ngang và dọc trong vùng điện áp dưới ngưỡng, độ dốc dưới ngưỡng của tranzito trường xuyên hầm dọc ban đầu giảm ở nồng độ cực nguồn thấp, sau đó tăng ở nồng độ trung bình, rồi lại giảm ở nồng độ cao. Trong khi đó, độ dốc dưới ngưỡng của tranzito trường xuyên hầm ngang luôn giảm theo hàm mũ khi tăng nồng độ cực nguồn. Với việc giảm độ biến thiên tạp chất cực nguồn, dòng mở của tranzito trường xuyên hầm ngang bị giảm mạnh, trong khi dòng mở của tranzito trường xuyên hầm dọc hầu như không đổi. Với những thuận lợi cơ bản về dòng mở, độ dốc dưới ngưỡng và kĩ thuật chế tạo, các tranzito trường xuyên hầm dọc sử dụng vật liệu vùng cấm nhỏ rất thích hợp dùng cho các mạch tích hợp công suất thấp.

Từ khóa: hiệu ứng tạp chất cực nguồn, kĩ thuật cực nguồn, xuyên hầm ngang, xuyên hầm dọc, tranzito xuyên hầm. 